Portugal 84 and the Bicentenary: checking fragments of the past

\section{| RESUMEN |}

Este escrito tiene como objetivo aportar a nuestra Facultad de Arquitectura y Urbanismo documentos fotográficos poco conocidos, cuando no desconocidos, sobre el barrio en el cual ésta se inserta, como asimismo exponer una escena habitual en nuestros patios, en tiempos ya pasados, cuando los vehículos motorizados aun no invadían los espacios que habitamos. También se esclarecen algunos datos en archivos extranjeros.

\section{| ABSTRACT |}

Two old pictures make it possible to look with a new perspective at the place where the University of Chile's School of Architecture and Urbanism is located today. The description and analysis of both pictures allow us to visit two specific moments in the urban and architectural history of the location. This can give us significant visual information when a possible transformation of the buildings is being discussed. It is to be hoped that the information and analysis presented in this article will be useful for a better understanding and preservation of the memories of this historic place. This, in turn, should help to better comprehend the present and plan the future of the site.

\title{
Portugal 84 y el Bicentenario: revisando fragmentos del pasado
}

\section{INTRODUCCIÓN}

Este año, el paréntesis que ha generado la celebración del Bicentenario de la Primera Junta de Gobierno, génesis de nuestra historia republicana, ha permitido que la vorágine a que nos ha acostumbrado la vida contemporánea nos permitiera, al menos por un corto tiempo, la reflexión acerca de nuestra identidad histórica, la rememoración y la revisión de nuestro pasado.

Acorde a esta circunstancia, y en un momento en que se discute cómo remodelar el recinto que ha cobijado nuestro quehacer universitario desde el año 1976, luego de la reestructuración decretada desde el $1^{\circ}$ de septiembre de 2010 (Decreto Exento № 0020567 de 28 de julio de 2010, la Rectoría de la Universidad de Chile; Rector Sr. Víctor Pérez Vera) se presentan dos imágenes fotográficas poco divulgadas y, por lo mismo, posiblemente desconocidas para la mayoría. Por su antigüedad y notable valor iconográfico, estas reproducciones adquieren la condición de documentos que revelan dos momentos específicos de la memoria histórica del recinto en que funciona nuestra Facultad. Sirvan ellas, por tanto, de antecedente para revisar el pasado del ámbito que es parte de nuestra cotidianeidad -y del cual muchas veces no poseemos un conocimiento exacto de su naturaleza y condición histórica-, a fin de sustentar nuestro presente y proyectar el futuro.
La imagen fotográfica como representación concreta de la realidad, resulta de suma utilidad e importancia a efecto de reconocer el pasado, a pesar del grado de subjetividad que toda creación humana conlleva. A modo de relato explícito, la imagen fotográfica revela a quien la observa una circunstancia espacio tempora difícilmente imaginable o reconocible de otro modo, la cual, inusitadamente, se hace patente al momento que la mirada del observador la escudriña. Mediante la fotografía nos asomamos al pasado y el pasado aparece ante nosotros para interpelarnos, desafiando nuestra conciencia y alentando una actitud reflexiva ante la inapelable evidencia histórica.

\section{EN EL ENTUSIASMO POR «VALPARAÍSO»,} UN ERROR DE CLASIFICACIÓN

La imagen presentada (IMAGEN 1) proviene del Catálogo fotográfico de la Comisión Científica del Pacífico, Colección Chilena 1863-1864. Archivos de la Biblioteca General de Humanidades y del Museo Nacional de Ciencias Naturales de Madrid, del Consejo Superior de Investigaciones Científicas español (CSIC). Número Registro (0001014) ABGH000/125/519; Castro y Ordóñez, Rafael; (Valparaíso) [sic] 1863-02-06/1864-10-11; ] fotografía sepia, copia en papel albuminado

Arquitecto Universidad de Chile, 1982. Académico Departamento de Historia y Teoría de la Arquitectura. Facultad de Arquitectura y Urbanismo. Universidad de Chile. Profesor de Historia de la Arquitectura Chilena. 
1. En el entusiasmo por "Valparaíso», un error de clasificación.

a partir de negativo sobre placa de vidrio al colodión húmedo; 208 × 268 mm. Fotografía reproducida en Rafael Sagredo B. y Miguel Ángel Puig-Samper M. (editores), IMÁGENES DE LA Comisión Científica del Pacífico en Chile, Editorial Universitaria, Santiago de Chile, 2007.

El catálogo referido fue conformado y posteriormente difundido a partir del año 1995 luego del hallazgo de diversos documentos relacionados con el archivo del naturalista historiador Marcos Jiménez de la Espada en la Biblioteca General de Humanidades del CsIC, donde se encontraban olvidados. Formando parte de dicho repositorio documental se encontraron más de quinientas fotografías correspondientes a la «Expedición del Pacífico» comisionada bajo el reinado de Isabel II para recorrer diversos países de América entre los años 1862 y 1864 . En el caso chileno, la visita de los expedicionarios españoles se verifica de fines de marzo de 1863 a mediados de junio del mismo año y de diciembre de 1863 a principios de octubre de 1864. Compuesta por diferentes científicos la Expedición del Pacífico además contó con Rafael Castro y Ordóñez como «personal auxiliar» cumpliendo funciones de fotógrafo y dibujante. De la labor fotográfica realizada por Castro y Ordóñez importa señalar el registro referido a las ciudades de Valparaíso y Santiago, los únicos dos casos urbanos que se documentan, sobresaliendo en cantidad las imágenes captadas de la ciudad puerto.

El número de registro clasifica la imagen presentada como vista de "Valparaíso», designación que para un observador conocedor de la condición local es inexacta. El análisis de los elementos reproducidos en la fotografía inmediatamente invalida la designación propuesta en el catálogo; la majestuosa cordillera con sus cumbres nevadas que constituye el fondo dominante de la imagen y la generosa amplitud de la geografía del lugar no se condicen con la realidad del paisaje propio a la ubicación geográfica de Valparaíso. Baste señalar que la Cordillera de Los Andes es imposible de ver a «vista de pájaro» desde Valparaíso, y la explanada del Almendral no alcanza la extensión ni la conformación que muestra la fotografía. Por su parte, teniendo en cuenta la presencia de los miembros de la Comisión Científica del Pacífico en Santiago en los meses de mayo y junio de 1863, cuando

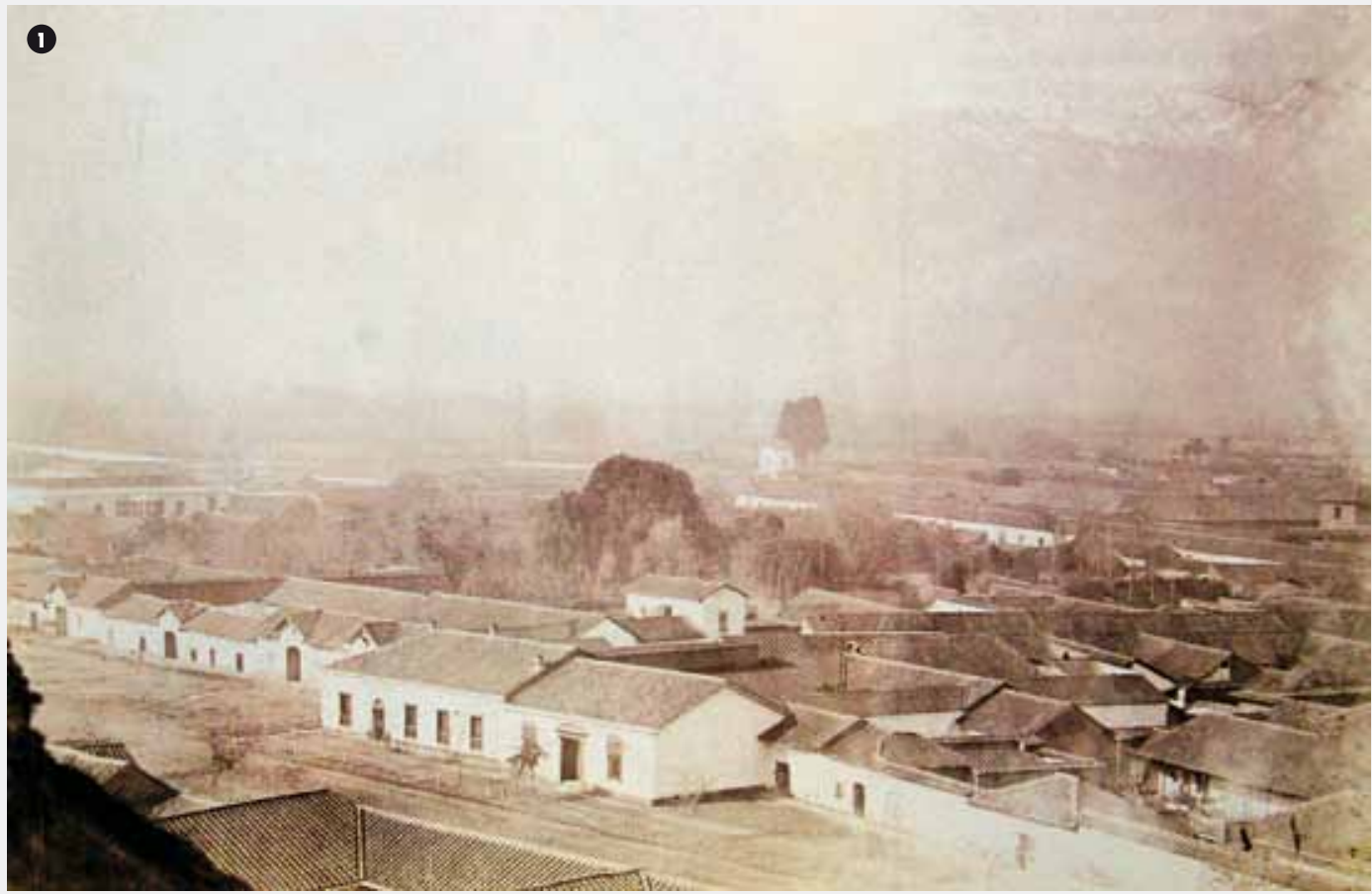

se registraron diferentes tomas fotográficas, necesariamente se desprende que la imagen en cuestión corresponde a Santiago y no a Valparaíso.

La toma fotográfica se realizó desde la altura mirando hacia el sur, dada la ubicación de la cordillera al oriente y la iluminación del sol, ya cercano el mediodía, que se despliega generoso sobre las fachadas de los edificios en primer plano y que miran, por lo tanto, hacia el norte. El lugar elegido para la captura fotográfica corresponde a un promontorio tal como lo delata la forma sombreada que aparece en el vértice inferior izquierdo de la fotografía. La ventajosa elevación -se estima una altura de 20 metros- permite una vista amplia y profunda del paisaje advirtiéndose la presencia de construcciones en la parte baja inmediata, las cuales enfrentan, extenso espacio de por medio, las construcciones inicialmente comentadas. Destaca, además de los edificios de marcada tradición colonial, la presencia importante de masas arbóreas abarcando gran extensión de terreno, las cuales se tornan más dominantes en la medida que la perspectiva se hace más profunda y el paisaje se torna rural. Ello permite afirmar que el área retratada es, por tanto, un sector perimetral al suroriente de la ciudad de Santiago iniciada la segunda mitad del siglo xIX.

Se propone que la fotografía corresponde a una toma desde el Cerro Santa Lucía mirando al suroriente, aproximadamente a la altura de la actual calle Portugal. Esta interpretación se basa y corrobora al confrontar la imagen presentada con otras fuentes iconográficas de data similar. Ellas corresponden a dos dibujos, a modo de vistas panorámicas de Santiago, realizados desde el mismo punto de observación, el cerro Santa Lucía, aunque desde una ubicación superior. Además se compara con una fotografía del año 1874

La primera imagen comparada es la reproducción de una litografía de T. Sinclairs obtenida de un dibujo atribuido a E.R.

Smith quien lo realizó usando como base un daguerrotipo, y que forma parte del informe de la Misión Astronómica de la Marina de los EE.UU., al mando del teniente de marina James Melville Gilliss, The United States Astronomical EXPEDITION TO THE SOUTHERN HEMISPHERE DURING THE YEARS 1849-'50-'51-'52. Vol. I (Washington, 1855). Esta panorámica, de la cual se señala existe un original en el Museo Histórico, aparece reproducida en el ReSUMEN DE LA HISTORIA DE CHILE 
2. Dibujo según croquis en daguerrotipo, por E.R. Smith, litografía de T. Sinclairs, 1855. Fuente: Lámina 10 en: Encina, Francisco A., Resumen de la historia de Chile, Tomo II, Segunda Edición, Editorial Zig Zag, 1956. Ver: www.santiagorepublicano.cl

3. Sección de croquis en daguerrotipo, por E.R. Smith, litografía de T. Sinclairs, 1855. Fuente.: Lámina 10 en: Encina, Francisco A., Resumen de la historia de Chile, Tomo II, Segunda Edición, Editorial Zig Zag, 1956.

4. Vista jeneral de la ciudad de Santiago de Chile. Tomada del cerro Santa Lucía, por don Pedro Dejean Arqto. Fuente: Lámina 12 en: Encina, Francisco A., Resumen de la historia de Chile, Tomo II, Segunda Edición, Editorial Zig Zag, 1956. Ver: www.santiagorepublicano.cl

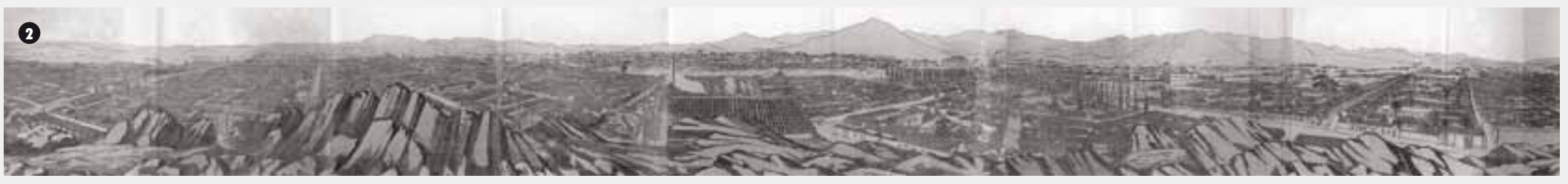

(VOL. II) de Francisco A. Encina. Corresponde a una vista de la ciudad de Santiago realizando un barrido en $360^{\circ}$, de izquierda a derecha, el cual se inicia mirando hacia el surponiente. La sección relacionada con la fotografía en análisis se ubica en el extremo derecho de la vista general de la cual se presenta el detalle ampliado. En éste se aprecia, de derecha a izquierda, la fachada sur de la Alameda entre las actuales calles Carmen y Portugal, apareciendo primeramente la iglesia del Monasterio del Carmen Alto y a continuación unas viviendas con sus fachadas principales mirando la Alameda. Al oriente de la calle Portugal se despliega igualmente una extensa fachada continua de viviendas donde destacan los característicos mojinetes que marcan sus accesos. La calle Portugal, aparece claramente conformada por construcciones contiguas a lo largo de su recorrido en esa época, las cuales esconden generosos huertos y jardines (IMÁGENES 2 × 3$)$.

La segunda imagen (IMAGEN 4 Y 5), VISTA JENERAL de LA CIUDAD de SANTIAGO de ChILE, es similar a la anterior y fue ejecutada por el arquitecto francés Pierre Dejean. En este caso, eso sí, el recorrido de la visión del observador se inicia mirando hacia el sur para luego ir girando hacia el poniente, norte, oriente y terminando

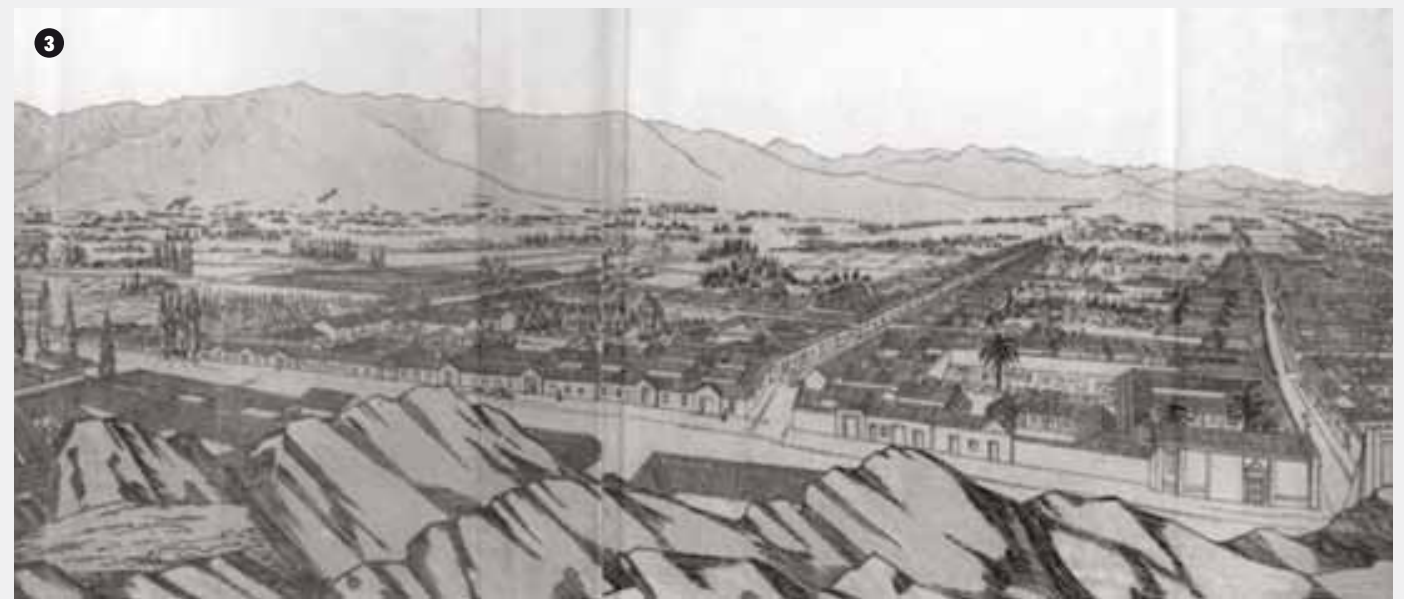

cerca del punto inicial de observación. Debido a ello en esta ocasión el punto de interés a reconocer se ubica en el extremo izquierdo de la vista general, el cual ha sido igualmente ampliado. De izquierda a derecha se muestra en primer término la actual calle Portugal enfilando hacia el sur y luego la actual calle Carmen, registrando, por tanto, la misma vista de ese tramo sur de la Alameda y del área tras de él. Se observa en esta ocasión, una representación menos fidedigna que la anterior en cuanto a los detalles. Respecto de la data de esta panorámica, si bien en la lámina se indica el año de 1867, dicha fecha puede corresponder a la fecha de su publicación pero no necesariamente a la fecha en que Dejean la ejecutó. La versión que aquí se presenta es la que se incluye también en el RESUMEN DE LA hISTORIA De ChILE (VOL. II) de Francisco A. Encina.

El análisis comparativo de las dos panorámicas presentadas con la fotografía realizada por Castro y Ordóñez en 1863, revelan diversas coincidencias en la condición general y en los detalles. La conformación urbano-arquitectónica y el carácter del lugar presentan las mismas

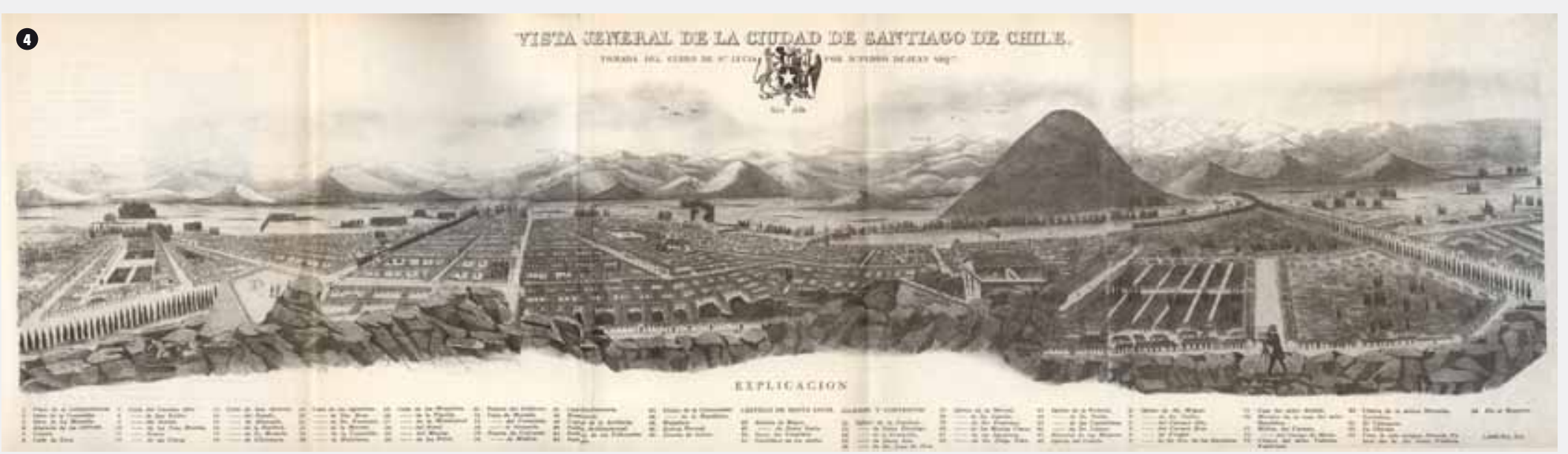


5. Sección de Vista jeneral de la ciudad de Santiago de CHILE. Tomada del cerro Santa Lucía, por don Pedro Dejean Arqto., 1867. Fuente: Lámina 12 en: Encina, Francisco A., Resumen de la historia de Chile, Tomo II, Segunda Edición, Editorial Zig Zag, 1956.

6. Vista desde el «divisadero» del Santa Lucía. Fuente: Álbum del Santa Lucía. 1874. Imprenta de la Librería del Mercurio, Santiago, Chile. Reproducida en: Pérez de Arce, R y otros. La montaña mágica - El cerro Santa Lucía y la ciudad de Santiago. Ediciones ARQ, Santiago, 1993.

características. El encuadre fotográfico, está orientado más hacia el suroriente en la imagen de Castro y Ordóñez, menos frontal respecto de la Alameda y a la vez más retrasado respecto de la ahora calle Portugal, dificulta el reconocimiento de dicha calle hacia el sur. De ésta sólo se infiere su existencia por las dos líneas paralelas de las cumbreras corridas de las construcciones que conforman los dos flancos de la calle en su recorrido en dirección sur.

El único aspecto discordante que presenta la fotografía de 1863 respecto de las dos vistas panorámicas son las dos construcciones -seguramente viviendas- que se adelantan en forma protagónica del plano continuo de fachada en el costado sur de la Alameda al oriente del Monasterio del Carmen Alto, configurando la esquina surponiente de la actual calle Portugal con Alameda. Dicha alteración morfológica del plano continuo de fachada, no aparece en las panorámicas de Smith y Dejean, lo cual sugiere que esas construcciones fueron levantadas en el período entre la realización de ambas vistas generales y el año 1863. Una nueva fotografía de 11 años después (IMAGEN 6) viene a corroborar y completar la interpretación que se ha realizado. Ésta corresponde a una de las imágenes incluidas en el ÁlbUM DEL SANTA LuCía y que, desde el lugar llamado el "divisadero», captura una toma muy similar a la fotografía de 1863. En el texto que acompaña la imagen se señala que la toma se realizó desde la plataforma del castillo de González, sitio de antigua data en la geografía del cerro. En la fotografía se observa el mismo paraje y la anomalía morfológica en el tramo al oriente del Carmen Alto se ha regularizado mediante la erección de un tapial que recupera la continuidad de fachada y redefine el perfil de ese tramo de la Alameda. A favor nuestro, esta nueva imagen del sector, realizada presumiblemente por Pedro Adams de Garreaud y Cía. (Rodríguez, 2001), amplía la visión hacia el sur entregando mayores detalles del sector donde hoy se levanta nuestra Facultad de Arquitectura y Urbanismo.

Desde un punto de vista histórico es interesante resaltar que la fotografía de Castro y Ordóñez es un medio de prueba que, con la evidencia de las dos viviendas que se construyen sobre la Alameda fuera de la línea de edificación,
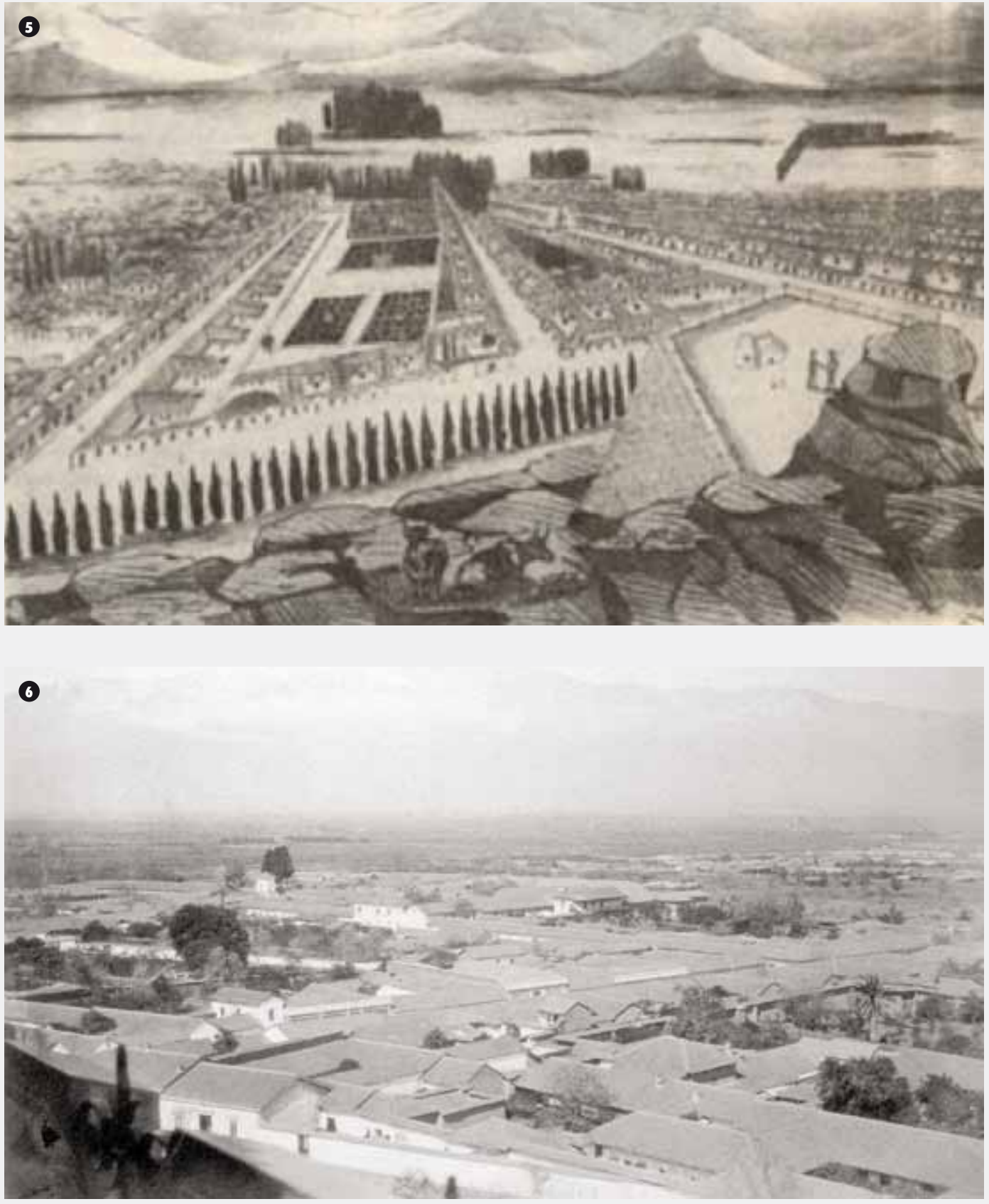

verifica que la tradición constructiva colonial está aún plenamente vigente ya avanzadas varias décadas del siglo XIX. Así se reconoce en el carácter y morfología de ambas construcciones.

la documentación realizada. En este caso el encuadre fotográfico es de mayor ángulo visual permitiendo apreciar de mejor manera el paisaje general y advertir con mayor claridad el inicio hacia el sur de lo que era en aquellos años la actual calle Portugal.
Existe, finalmente, una cuarta imagen de época, sin fecha ni autor (IMAGEN 7), la que igualmente incorporamos para complementar 


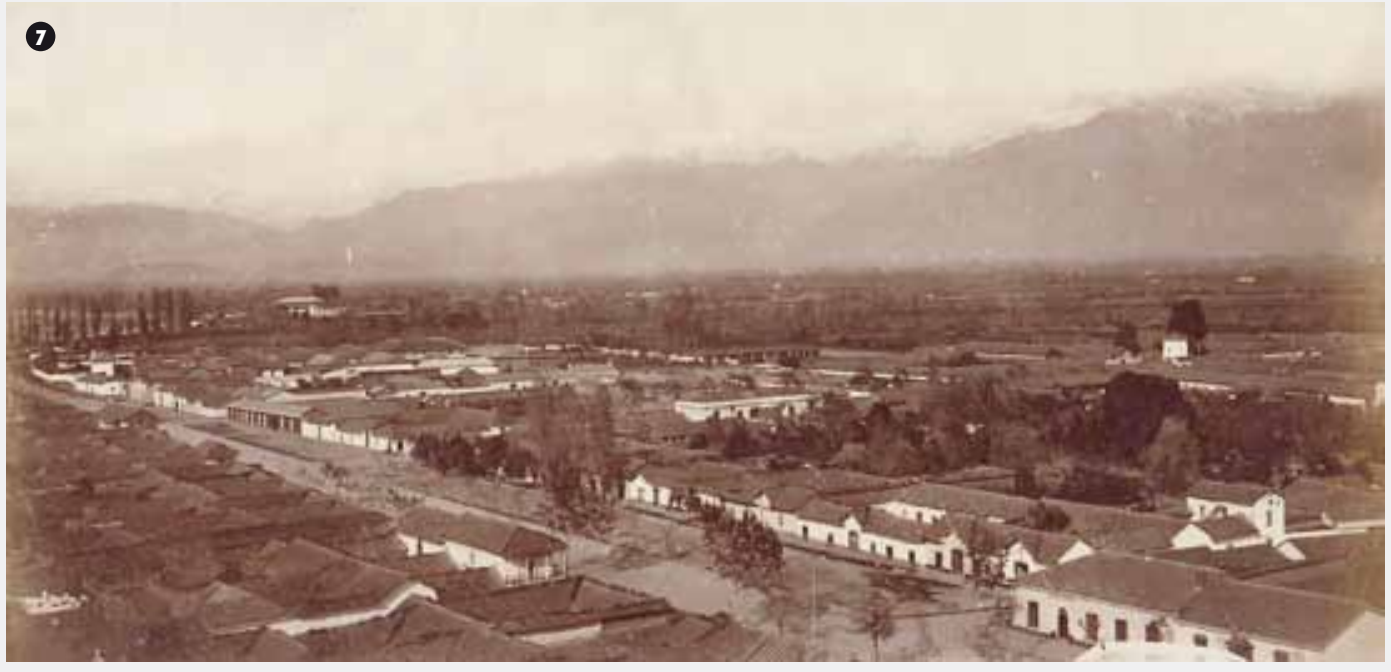

Al igual que en la toma fotográfica de Castro y Ordóñez sorprende la escena de Santiago reproducida. Su situación de periferia urbana mantiene inalterable y homogéneo el carácter colonial de la ciudad -ya en vía de transformarse y luego desaparecer- el cual se funde armónicamente con el marco natural y la majestuosidad de la Cordillera de Los Andes. Quizás haya sido ésta la razón por la cual Castro y Ordóñez privilegió esta toma de Santiago desde el cerro Santa Lucía, en vez de retratar la vista más urbana de la ciudad hacia el poniente, ya que destaca la originalidad y belleza paisajística de este sector en el Santiago de aquellos años.

Verificada, por comparación documental, la catalogación propuesta para la fotografía de Castro y Ordóñez como imagen de la ciudad de Santiago, se hará un breve relato histórico del sector ahora ya reconocido en propiedad.

Tal como se planteó inicialmente el sector retratado en 1863 por el fotógrafo español se aprecia como un área en la periferia de la ciudad de Santiago, lo cual queda de manifiesto en el carácter tradicional de su imagen urbanoarquitectónica que, ya iniciada la segunda mitad del siglo XIX, aún no era alterado por las transformaciones edilicias que estaban teniendo lugar en la parte central de la ciudad. Igualmente, la inexistencia de la retícula en damero dice de un sector de desarrollo urbano que difiere en su origen al del núcleo fundacional y que se ha ido conformando con un carácter particular a través del tiempo. De ello da cuenta la dimensión predial y la presencia importante de la vegetación como ya ha sido comentado. Es la herencia de la antigua ocupación que tuvo lugar en este sector de la ciudad destinado a chacras agrícolas suburbanas, siendo la más importante de ellas la que perteneció a la Orden de la Compañía de Jesús (100 cuadras de extensión donadas en 1595 por el capitán de la conquista Agustín Briceño), donde los jesuitas establecieron una residencia, siendo conocida como Chacra de la Ollería. El lugar recibió esa denominación debido a que en dicho lugar los jesuitas instalaron una industria destinada a producir loza para abastecer la demanda de vajilla de los habitantes de Santiago. Según Vicuña Mackenna la producción de alfarería era una tradición en este sector de la ciudad que se remontaba incluso a la época prehispánica, actividad que no fue desarrollada solamente por los jesuitas si no que se siguió practicando por gran parte de la población que habitó ese apartado sector de Santiago colonial (Vicuña Mackenna, 1902). Es por ello que el primer nombre que conoció la actual calle Portugal fue el de calle o callejón de la Ollería el cual se mantuvo durante todo el período colonial.

A los jesuitas se debió también, iniciado el siglo XVIII, la incorporación en los terrenos de la Ollería de una Casa de Ejercicios espirituales gracias al aporte económico del capitán Miguel de los Ríos -costado poniente de la calle del mismo nombre avanzando al sur algo más de una cuadra desde la Cañada-, inmueble al que posteriormente se le comenzó a denominar simplemente San Ignacio. En 1752 se levantó una segunda Casa de Ejercicios, con el patrocinio de Don Juan Antonio Araoz, al frente de la primera-calle de por medio- recibiendo el nombre de Nuestra Señora de Loreto. Ésta se ubicaba en los terrenos que ahora ocupa nuestra Facultad y, a diferencia de la primera, recibía tanto a hombres como a mujeres que realizaban los retiros espirituales en áreas independientes, en torno a patios, separados por una capilla situada al medio del conjunto (Hanisch, 1974). La disponibilidad de terreno y la condición apartada del lugar deben haber sido los factores que favorecieron la instalación de ambas casas de retiro que hicieron aún más conocida esta calle del Santiago colonial, la cual servía además como vía que, avanzando en dirección sur, conectaba con el inicio del camino que conducía al pago de Ñuñoa-actual calle Irarrázaval- (León Echaiz, 1972).

La expulsión de los jesuitas de todos los dominios del imperio español en 1767 significó el traspaso de la chacra de la Ollería y sus instalaciones al Obispado de Santiago que la administró por algunas décadas para posteriormente, ya iniciado el siglo XVIII, iniciar un proceso de transformación. En primer término, lo que fuera la casa de San Ignacio fue adquirida en 1804 para el Estado por el gobernador Luis Muñoz de Guzmán con la intención de instalar en dicho lugar un hospicio, a cuyo objetivo contó con la colaboración de Manuel de Salas. El Hospicio comenzó a funcionar a mediados del citado año y, ya varios años después, en 1873, fue dotado de una capilla que adquirió la condición de iglesia pública en 1879 bajo la advocación de Nuestra Señora de los Dolores (Arancibia, 1980).

Por su parte, la antigua Casa de Ejercicio Nuestra Señora de Loreto fue confiscada por el gobierno patriota en 1817, luego de la batalla de Chacabuco, para reinstalar en su recinto la maestranza de material de guerra en los apremiantes días en que se libraban las luchas cruciales por la Independencia Nacional. Vicuña Mackenna en su estilo lírico exalta la figura del fraile franciscano Luis Beltrán, quien asumió la dirección del establecimiento el cual fue fundamental para la causa patriota y dentro de cuyos muros la población de Santiago colaboró, 
8. Sección del Plano de SAntiago de Ernesto Ansart, 1875 Fuente: Martínez, René. Santiago de Chile. Los planos de su historia. Municipalidad de Santiago, Santiago, 2007.

infundida de espíritu libertario, reparando las armas estropeadas en Cancha Rayada y fundiendo los cañones y municiones que dieron al Ejército Libertador la victoria en el campo de Maipo el 5 de abril de 1818 (Vicuña Mackenna, 1902).

La Maestranza, de tan glorioso origen, continuó funcionando en el lugar una vez finalizado el proceso independentista, aprovechando las ventajas del extenso y aislado terreno disponible y consolidándose como establecimiento industrial y enclave militar en el antiguo sector Diversos planos de la ciudad de Santiago dan cuenta de ello. El plano de Herbage de 1841 señala el lugar como «Cuartel de artillería y maestranza», incorporando por tanto una función militar adicional. Posteriormente, en el año 1842 el recinto de la Maestranza acogió una nueva e importante función: la Academia Militar (Escuela Militar desde 1843). Ésta inicia en este lugar su historia definitiva luego de algunos intentos fallidos a partir de 1817. El plano de 1852 publicado por Gilliss en base al levantamiento realizado por oficiales de la Academia Militar registra el lugar como «Military Academy», y el plano de Esteban Castagnola, profesor de dibujo, en 1854, identifica el funcionamiento compartido en el lugar de la «Escuela Militar y el Cuartel de Yungay». Dejean en 1856 lo señala como "Maestranza o Academia Militar». Finalmente, el plano levantado por T. Mostardi Fioretti (1864) sólo identifica el lugar como «Academia Militar». Es en este plano donde por primera vez el nombre de la antigua calle de la Ollería ha sido cambiado al de Maestranza, nueva denominación que reconoce la importancia y fama de este establecimiento militar en el Santiago de aquellos años que desplaza el recuerdo de la otrora fábrica alfarera.

Esa era, por lo tanto, la condición del lugar al momento de la fotografía realizada por Castro y Ordóñez y complementada con la imagen de 1874 del ÁlbUM del SANTA LuCía. Las instalaciones militares ocupan un extenso terreno en el cual se reconoce en la parte delantera, hacia la calle de la Maestranza, el follaje de los otrora claustros y patios de la casa de ejercicios de Nuestra Sra. de Loreto, donde funciona la Escuela Militar, mientras que en la parte oriente de la propiedad se advierte un importante conjunto edificado donde se ubicarían las instalaciones de la

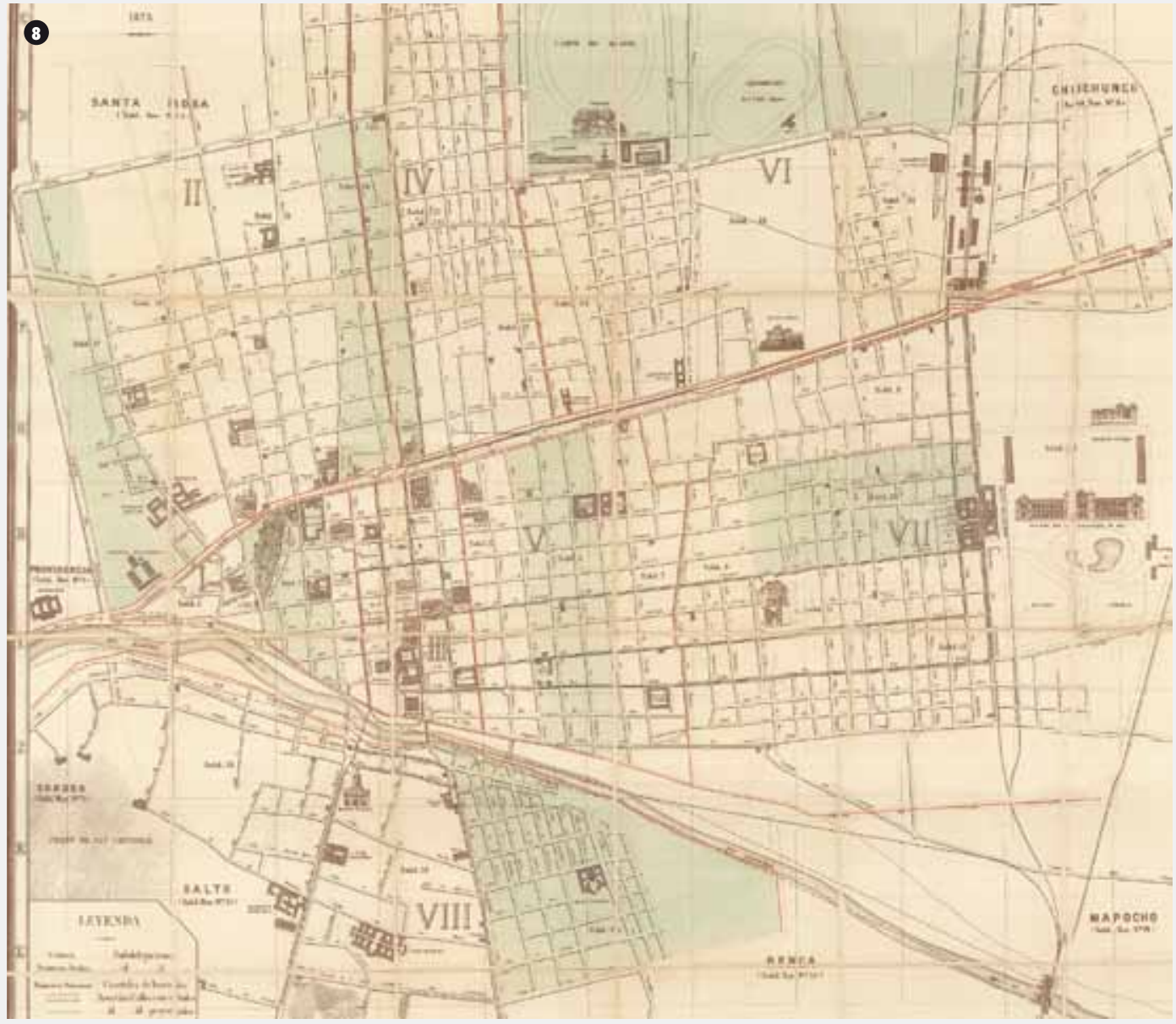

maestranza propiamente tal. Como antecedente final se adjunta un plano de Santiago del año 1875 levantado por Ernesto Ansart que, aunque posterior a la fecha de 1863, es más fidedigno que otras fuentes planimétricas (IMAGEN 8). En él, norte abajo, aparece a la derecha la calle de la Maestranza y la representación de la silueta de planta del conjunto de la Escuela Militar. No deja de llamar la atención, sin embargo, que tanto en este plano como en otros se reconoce como construcción militar destacada sólo la Escuela Militar, sin reproducir el total del enclave militar, dejando de lado la identificación del recinto de la Maestranza en propiedad que, de acuerdo a las fotos de 1863 y 1874, es significativo, abarcando una considerable cantidad de terreno con importantes construcciones más al oriente de la Escuela Militar.

\section{CAZADORES DEL GENERAL BAQUEDANO Y PISADAS EQUINAS EN NUESTRO PATIO}

La imagen ha sido obtenida del álbum fotográfico CHILE AL DíA. ÁlBUM GRÁFICO DE VISTAS DE CHILE. TOMO I. Hume y Walker Editores, Santiago, Chile, 1916. Vista 7: Ejército Chileno. Caballería. "Cazadores General Baquedano» de guarnición en Santiago». A fin de entender la naturaleza del origen de esta imagen observamos la presentación realizada por los editores de dicha publicación:

Ha sido una costumbre muy generalizada en los últimos tiempos en las naciones más adelantadas, para dar a conocer sus progresos y el valor real que tienen, como la situación que ocupan en el orbe, el presentar al extranjero álbums [sic] gráficos que pongan ante su vista, en forma expresiva, llamativa, sincera, sus 


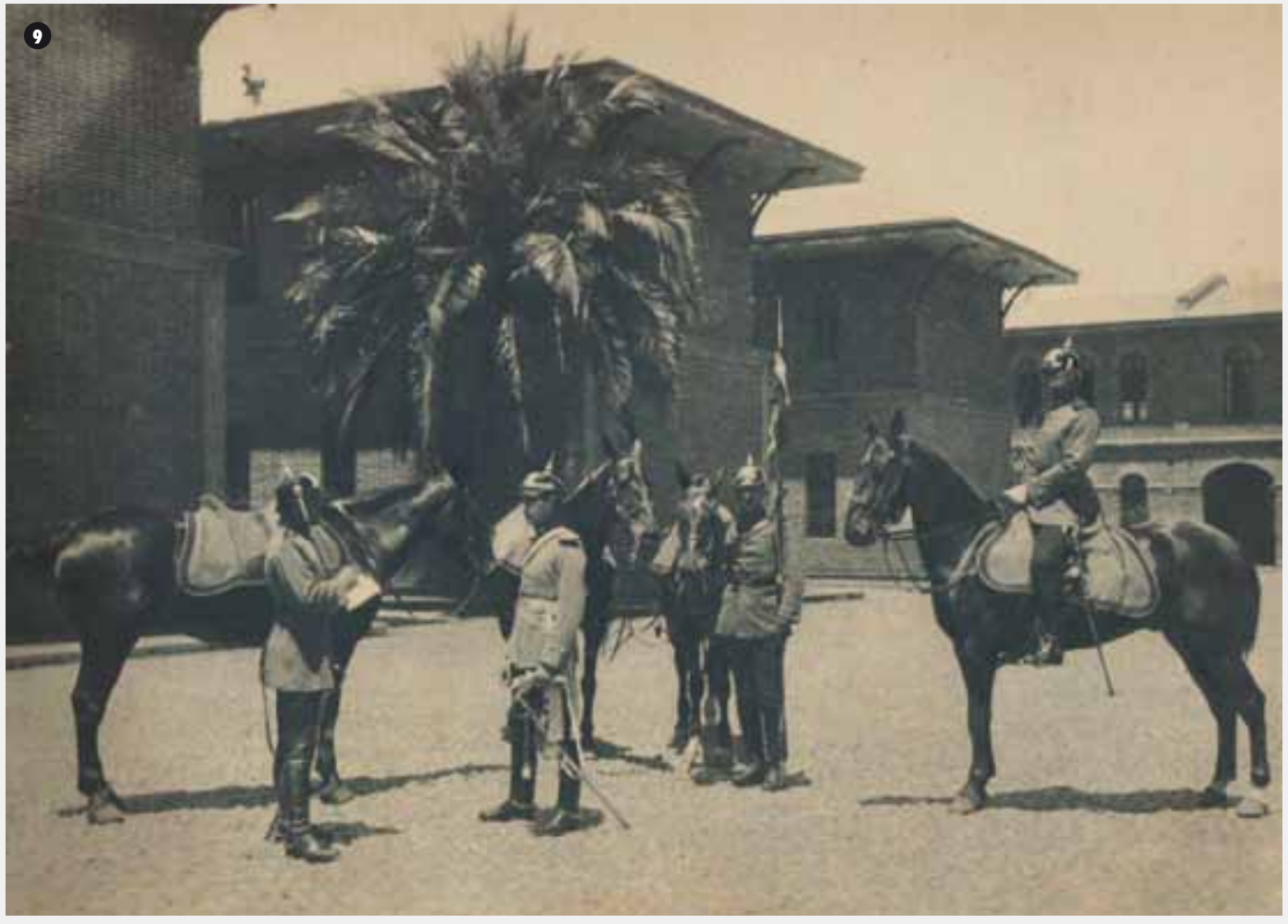

ciudades y sus campos, sus montañas y sus ríos, sus medios productores de la riqueza pública y privada, sus establecimientos más importantes que enseñan y educan, sus centros comerciales, sus monumentos y sus paseos y todo aquello en fin que significa adelanto, civilización.

Mas, no sólo con estos álbums [sic] se logra atraer la atención del extranjero hacia el país que se le describe tan amenamente, sino que, aún, cuando la obra es elegante, presentada con arte, y metódica, causa sensación de belleza, deleita y educa.

Los asombrosos progresos alcanzados últimamente por la fotografía y demás procedimientos gráficos, permiten realizar obras realmente bellas, tanto en su fondo, que reflejen la verdad de la naturaleza, como en su forma artística (...).

CHILE AL Día, es pues un álbum que presenta en forma gradual y sistemática cuánto de hermoso tiene el país, y no sólo sus paisajes, de sus ciudades, de sus monumentos, sino de sus instituciones y sociabilidad.
El álbum en su Tomo I, organizado en seis entregas fotográficas (72 reproducciones), alterna distintos tipos de imágenes que dan un panorama variopinto de la realidad nacional. En cinco de las seis entregas se incluyen representaciones relacionadas con la función militar (9 fotografías) tanto de la marina (2 fotografías) como del ejército (7 fotografías).

La imagen, tal como lo señalan los datos adjuntos, muestra a cuatro oficiales del Regimiento de Caballería Cazadores General Baquedano retratados en uniforme de parada en el recinto que ocupaba dicha unidad del ejército el año que, presumiblemente, se realiza la fotografía (1916) (IMAGEN 9).

La toma logra representar una escena más bien distendida de un momento particular en la vida del cuartel castrense, no advirtiéndose la rigidez forzada de una pose preestablecida, sino que la intimidad previa, quizás, a un acto oficial o protocolar. En la composición fotográfica, cuatro militares y sus gallardas cabalgaduras configuran un primer plano de gran prestancia y simbolismo, quedando resaltados por la amplia explanada iluminada por una intensa luz solar en su cenit que inunda homogéneamente el plano de base. A su vez, el fondo queda definido por la sucesión de cuatro cuerpos edificados, mayoritariamente a semisombra dado los generosos aleros de cada una de las techumbres, y el importante follaje de una palmera. La disposición de los edificios y su dimensión definen la profundidad de campo en perspectiva y colabora en resaltar y referir la escala a las figuras en primer plano. La ausencia de otro tipo elemento dentro del amplio espacio, que pudiese perturbar la escena, coadyuva a exaltar la monumentalidad del conjunto y la austeridad y orden propio a la vida castrense y a resaltar la intimidad del momento capturado.

Cabe destacar que el Regimiento de Caballería Cazadores forma parte de los primeros escuadrones militares que fueron creados en los albores de nuestra historia republicana, en aquellos críticos años en que la acción bélica demandó organizar el ejército patriota a fin de lograr y asegurar la independencia del dominio español en el período conocido como la Patria Nueva. Es por lo tanto una unidad militar de antigua data y significativa tradición histórica. Su origen se documenta como iniciativa del Director Supremo Bernardo O'Higgins en el año 1817, en la ciudad de Concepción, quien crea una compañía de Cazadores a Caballo «para atender oportunamente diversos puntos de la costa y otros objetivos interesantes al mejor servicio del Estado» (citado en Zepeda, 2005 p. 31). En noviembre de 1817 se oficializa la creación del nuevo regimiento de caballería al designarse como su primer Comandante al Coronel Ramón Freire, quedando conformado por una Plana Mayor y dos escuadrones, de dos compañías cada uno, con una dotación de 204 soldados. Los cazadores a caballo (también los había de infantería) eran unidades de caballería ligera que fueron creadas en Europa con un rol estratégico y de reconocimiento a fin de apoyar el desplazamiento de las tropas, lo cual les otorgaba importante protagonismo en el campo de batalla y gran prestigio, por lo mismo, dentro de la milicia de aquellos años. Cabe señalar, además, que en el caso de la compañía creada por O'Higgins le fue asignada la función específica de servir como escolta del Director Supremo, razón por la cual el nombre que adquirió la unidad fue el de "Cazadores a caballo de la Escolta Directorial», siendo una función que mantuvo en el tiempo 
10. Giovanni Mochi. El General Baquedano en la Batalla de Chorrillos, 1876. Fuente: Bindis, Ricardo. Pintura chilena. Doscientos años. Origo Ediciones, Santiago, Chile, 2006.

11. Giovanni Mochi. Carga de los Granaderos en la Batalla de Chorrillos. Fuente: Bindis, Ricardo. Pintura chilena. Doscientos años. Origo Ediciones, Santiago, Chile, 2006.

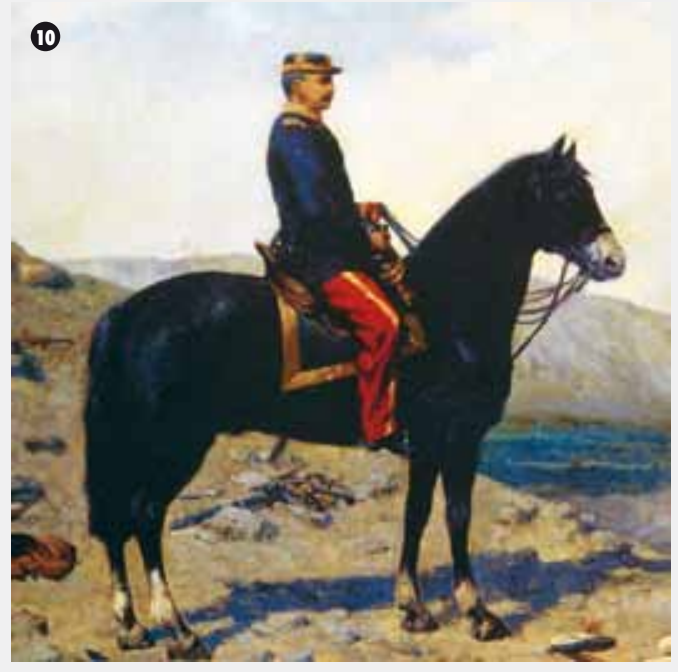

pasando a ser posteriormente la escolta presidencial.

El prestigio del regimiento se consolida rápidamente, de ello da cuenta su sobresaliente historia militar que se inicia con su participación en las batallas decisivas por la independencia nacional: Sitio de Talcahuano (noviembre 1817); Batalla de Quechereguas (marzo 1818); Sorpresa de Cancha Rayada (marzo 1818) y Batalla de los llanos de Maipo (abril 1818). Posteriormente, ya instalada la República, participa activamente en diversas batallas de la campaña militar contra los focos de resistencia realista en la zona sur del país, episodio histórico conocido como la Guerra a Muerte (1819-1822), como también en la guerra contra las montoneras de los hermanos Pincheiras (1826-1827 y 1830-1831). Posteriormente, los escuadrones del regimiento se ven involucrados en la Revolución de 1829-1830 participando tanto en la Batalla de Ochagavía como en la decisiva Batalla de Lircay. Luego de unos años de paz, y afianzado el orden político local, la guerra contra la Confederación Perú-Boliviana (1838-1839) fue una nueva circunstancia bélica en que el Regimiento de Caballería Cazadores sobresale en diversos combates, de los cuales el más importante es la Batalla de Yungay, donde la caballería fue determinante para dar la victoria a las fuerzas chilenas y lograr con ella poner fin a dicha guerra. Iniciada la segunda mitad del siglo XIX se sucede la participación del regimiento en las revoluciones de 1851 y 1859 , para luego tomar parte en la Pacificación de la Araucanía (1859-1869), y de 1879 a 1883

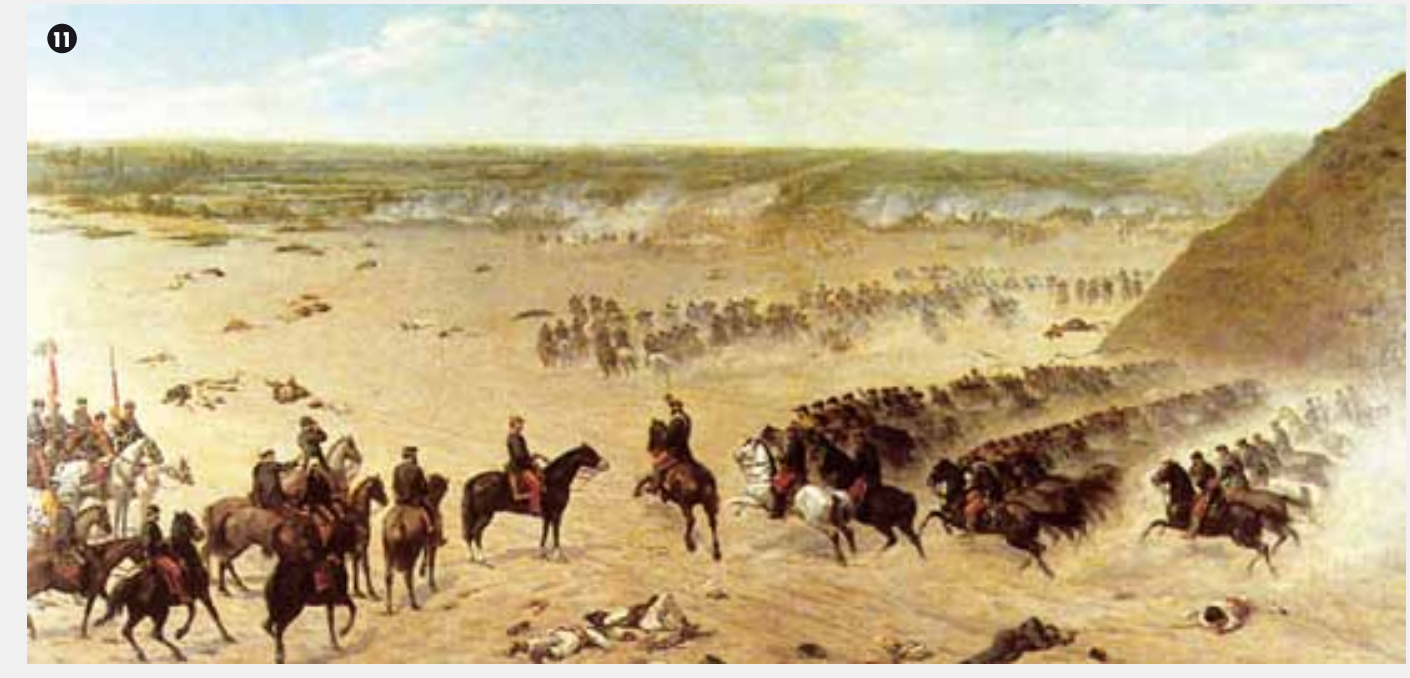

en las cinco campañas en que se desarrolló la Guerra del Pacífico. Es este último largo conflicto bélico, pleno de combates y gestas memorables, que comprometió a la sociedad toda, donde los Cazadores alcanzan quizás su mayor reconocimiento histórico. Dentro de los hombres que formaron parte de esta unidad de caballería, Manuel Baquedano González es el más ilustre y con quien más se identifica dicha institución. Fue su comandante entre los años 1869 y 1879, dejando dicho cargo al ser designado Comandante General de la Caballería. Posteriormente, dado sus méritos y capacidad, fue nombrado en 1880 Comandante en Jefe del Ejército en Campaña (IMÁGenes 10 y 11).

Luego de su larga participación en la Guerra del Pacífico, en el período de paz que se inicia, la unidad militar se reinstala en Santiago donde reasume su cometido de Escolta del Presidente de la República además de desarrollar la instrucción propia de la caballería.

Durante esos años el regimiento habría ocupado el antiguo Cuartel de Granaderos existente enfrente de la fachada principal del Palacio de La Moneda, quedando las pesebreras ubicadas en la cercana calle de San Ignacio. Esto último era causa de reclamos por parte del vecindario dado los inconvenientes a la salubridad que el ganado caballar ocasionaba. Ésta parece ser la principal razón que motivó la necesidad de encontrar una nueva ubicación para el regimiento ante lo cual el antiguo recinto militar de calle Maestranza resultó del todo apropiado.
La extensión del terreno y relativo aislamiento y la disponibilidad del lugar, luego que la Escuela Militar emigrara a un nuevo local, fueron los argumentos que avalaron la instalación del Regimiento en esta localización.

Demoliendo las antiguas construcciones y despejando el terreno de los añosos árboles de la otrora casa de ejercicios colonial, se levantaron las nuevas instalaciones militares que contemplaron un edificio principal enfrentando la calle Maestranza, tras del cual, de forma paralela, se dispusieron cinco volúmenes complementarios, en dos y un piso, destinando cuatro de ellos a alojamiento de la tropa (cuadras) y uno a comedores. El remanente de terreno hacia el oriente quedó destinado a picaderos, pesebreras y funciones complementarias. De acuerdo a fuentes orales (antecedentes comentados en su momento por el arquitecto Sr. Pedro Letelier Almeyda), estando el cuartel en etapas finales de construcción (1890), y antes de iniciar su función militar, algunos de sus pabellones fueron ocupados transitoriamente para servir de extensión del Hospital San Borja, ubicado inmediatamente al norte. Los edificios fueron utilizados para recluir a enfermos orates, los cuales ocuparon el inmueble hasta la Revolución de 1891, momento en que fue acantonado en el lugar el Regimiento Cazadores. Fue la circunstancia que determinó que los enfermos debieran abandonar el lugar siendo trasladados a las instalaciones que para manicomio se habían comenzado a construir en calle Olivos desde mediados del siglo XIX y que en lento avance aún no eran finalizadas. 
La fotografía del álbum de 1916 reproduce por lo tanto el local que había comenzado a ocupar de forma definitiva el regimiento -alrededor de 1893-posterior a los sucesos de 1891. La crisis institucional de dicho año tuvo como consecuencia la reorganización del ejército, y para esta unidad en particular significó su disolución. Luego de ser recreada como Escuadrón de Caballería № 2 en la ciudad de Angol (octubre 1891) y permanecer cerca de dos años en esa ciudad, recobra el grado de Regimiento y retorna a Santiago recuperando, además, la función de Guardia de Palacio y escolta presidencial e instalándose en propiedad en el local de calle Maestranza.

\section{La disposición volumétrica que presenta} el conjunto construido corresponde a un esquema de cuartel en bloques o pabellones independientes dispuestos paralelamente (Block System), solución propuesta en los tratados de arquitectura militar del siglo XIX como solución dominante y que se entiende como una partido moderno o reformista respecto del esquema tradicional de edificios organizado en torno a un patio central. Varias son las ventajas que dicha distribución asegura al independizar en pabellones cada una de las partes del programa requerido, entendiendo que la principal función de un cuartel militar es el permanente y adecuado alojamiento de una tropa de guarnición. La más importante dice relación con la posibilidad de proveer de ventilación, iluminación y asoleamiento a cada edificio y sus usos interiores, acogiendo los preceptos higienistas y de sanidad en boga en aquellos años. Las recomendaciones establecen disponer los pabellones norte-sur exponiendo sus flancos mayores al oriente y poniente, procurando asegurar un ángulo bajo de incidencia solar que permita a la benéfica luz del sol penetrar en las habitaciones al inicio y al término del día. A su vez la autonomía de cada pabellón respecto de los otros hace innecesarias las circulaciones y corredores exteriores que dificultan la ventilación y el asolamiento, con lo cual se privilegia un uso estricto y eficiente de la superficie construida y los consiguientes menores costos de ejecución. Por otra parte, la racionalidad funcional del sistema basado en la desagregación en partes permite mayor versatilidad para solucionar el partido arquitectónico, permitiendo enfrentar de mejor modo, sin la imposición de una forma preconcebida, la variable fundamental que plantea la forma del solar en todo proyecto arquitectónico. Como contrapartida se debe mencionar el hecho que para este sistema en pabellones se debe contar con un terreno de mayores dimensiones que en el caso de un sistema centralizado. Respecto del carácter estético, la tipología arquitectónica mantiene la severidad y solidez tradicional que es propia a un cuartel militar, sin mayores recursos ornamentales o de estilo en las fachadas que sólo ciertos énfasis formales que la misma solución constructiva sugiere. Haciendo uso de la piedra o el ladrillo para dar forma a las fábricas se reconocen elementos tales como: zócalos salientes, pilastras o cadenas en los vértices de encuentro de los muros, cornisas marcando los entrepisos, bandas enmarcando los vanos de puertas y ventanas, o el efecto dado a la disposición del aparejo de la fábrica de los muros.

La descripción tipológica precedente al ser contrastada con la imagen fotográfica que ha sido presentada demuestra la correspondencia que presenta el cuartel levantado en calle Portugal 84 con los principios de la arquitectura militar del siglo XIX, tal como fue señalado. Así el conjunto de pabellones de albañilería de ladrillo, con su especialidad característica, adquiere en el presente la condición de ejemplo escaso de una manifestación arquitectónica ligada al desarrollo histórico del ejército chileno en su condición de institución propia a las funciones del estado republicano. Quizás otro vestigio de la condición pretérita del lugar, aparte de las estructuras arquitectónicas que se conservan, sea la palma chilena, que en la foto de 1916 aparece ya con un importante crecimiento y que ciertamente es la misma que yergue en la actualidad en la misma ubicación, aunque con varios metros más de altura.

Como dato representativo, y a fin de comprender la dimensión del cuartel militar, se señala que al año 1895, luego de una reorganización administrativa y por Decreto Supremo $N^{\circ} 1.528$, de 31 de agosto de ese año, el Regimiento de Caballería № 2 "Cazadores» del General Manuel Baquedano González quedó organizado de la siguiente forma: una Plana Mayor compuesta por 10 oficiales y 31 hombres de tropa y 3 escuadrones, cada uno de ellos integrado por 5 oficiales y 82 hombres de tropa (Zepeda, 2005 p. 77).
Posteriormente, en el año 1924, una nueva organización determina que el Regimiento de Caballería pase a integrar la recién creada "División de Caballería», estableciéndose que quede organizado en 3 Escuadrones de Lanzas, 1 Escuadrón de Ametralladoras y una Sección de Comunicaciones (Zepeda, 2005 p. 87).

Las instalaciones erigidas a fines del siglo XIX para Regimiento de Caballería Cazadores cobijó a dicha unidad militar hasta el año 1933, cuando el cuartel fue trasladado a una nueva ubicación en calle Antonio Varas. En ese momento, ya pasados cerca de 40 años, el funcionamiento del regimiento presentaba nuevamente algunos inconvenientes en la ahora denominada calle Portugal, ex Maestranza (renombrada así a partir de las fiestas del Centenario). El desarrollo urbano de la ciudad y el deterioro de la infraestructura determinaron el cambio de local a un lugar más espacioso y retirado. Con ello se pone fin en el lugar a un desarrollo histórico centenario ligado a la función militar iniciado en los albores de la República y donde tuvieron lugar importante hechos y en donde importantes instituciones fueron acogidas. Cuando nuestra Facultad se instaló en Portugal 84, se rindió homenaje al Regimiento de Caballería № 2 «Cazadores» instalando una placa recordatoria en su hall central.

\section{BIBLIOGRAFÍA}

Arancibia, R. Parroquias de la Arquidiócesis de Santiago. 1840-1925. Imprenta San José, Santiago de Chile, 1980.

Bindis, R. Pintura chilena. Doscientos años. Origo Ediciones, Santiago de Chile, 2006.

Encina, F.A. Resumen de la historia de Chile, Tomo II, Segunda Edición. Editorial Zig Zag, Santiago de Chile, 1956.

Gillis, J.M. The United States Astronomical Expedition to the southern hemisphere during the years 1849-50-52. 2 vols. Washington, EE.UU., 1855.

Hanisch, W. Historia de la Compañía de Jesús en Chile. Editorial Francisco de Aguirre, Buenos Aires, Argentina, 1974.

Hernández, J.C. «Gerónimo Amici y los proyectos de cuarteles para regimientos de caballería de Andalucía, en la provincia de Huelva». En: Espacio, 
tiempo y forma, Serie VII, Historia del arte, Tomo 4, 1991, págs. 239-264. Archivo pdf en http://e-spacio.uned.es/ fez/eserv. php? pid=bibliuned:ETFSerie7E79E2CF0-1252-5A69-E6C298ACF1344D66\&dsID=PDF

León Echaiz, R. Nuñohue. Editorial Francisco de Aguirre, Buenos Aires, Argentina, 1972.

Martínez, R. Santiago de Chile. Los planos de su historia. Municipalidad de Santiago, Santiago de Chile, 2007.

Military Buildings Selection Guide. Heritage Protection Department March 2007. http:// www.english-heritage.org.uk/publications/ military-buildings/militarybuildings.pdf/

Pérez de Arce, R. y otros. La montaña mágica - El cerro Santa Lucía y la ciudad de Santiago. Ediciones ARQ, Santiago de Chile, 1993.

Ponce Ortiz de Insagurbe, Mercedes. Las fuentes documentales para el estudio de la historia de la construcción militar de los siglos XVIII y
XIX. 2000. http://gilbert.aq.upm.es/sedhc/ biblioteca_digital/Congresos/CNHC3/ CNHC3_099.pdf

Rodríguez, H. Historia de la fotografía. Fotógrafos en Chile durante el siglo XIX. Centro Nacional del Patrimonio Fotográfico, Impresora y Editora Ograma, Santiago de Chile, 2001

Sagredo, R. y Puig-Samper, M. (editores). Imágenes de la Comisión Científica del Pacífico en Chile. Editorial Universitaria, S.A., Santiago de Chile, 2007.

Sebastián, J.A. «Planimetría del cuartel español del siglo XIX». En: Anuario del Departamento de Historia y Teoría del Arte (U.A.M.) Vol. IV. 1992. Archivo pdf en http://digitool-vam. greendata.es:80//exlibris/dtl/d3_1/apache_ media/19479.pdf

Vicuña Mackenna, B. Álbum del Santa Lucía. Colección de las principales vistas, monumentos, jardines, estatuas i obras de arte de este paseo, dedicado a la Municipalidad de Santiago por su actual Presidente B. Vicuña Mackenna. Imprenta de la Librería del Mercurio, Santiago de Chile, 1874.

Vicuña Mackenna, B. Una peregrinación a través de la ciudad de Santiago. Guillermo E. Miranda Editor, Santiago de Chile, 1902.

Zañartu, S. Santiago: calles viejas. Editora Nacional Gabriela Mistral, Santiago de Chile, 1975.

Zepeda, J. Historia del Regimiento de Caballería Blindada N² «Cazadores». 1871-2002. Imprenta Austral, Puerto Montt, Chile, 2005. 